\title{
LY6K is a novel molecular target in bladder cancer on basis of integrate genome-wide profiling
}

\author{
R Matsuda', H Enokida*,', T Chiyomaru', N Kikkawa², T Sugimoto², K Kawakami', S Tatarano', H Yoshino', \\ K Toki', Y Uchida', K Kawahara ${ }^{3}, K^{\prime}$ Nishiyama', N Seki ${ }^{2}$ and M Nakagawa' \\ 'Department of Urology, Graduate School of Medical and Dental Sciences, Kagoshima University, 8-35-I Sakuragaoka, Kagoshima 890-8520, Japan; \\ ${ }^{2}$ Department of Functional Genomics, Graduate School of Medicine, Chiba University, Chiba, Japan; ${ }^{3}$ Kawahara Nephro-urology Clinic, Kagoshima, Japan
}

BACKGROUND: The aim of this study is to find a novel molecular target based on chromosomal alteration and array-based gene expression analyses in bladder cancer (BC). We investigated a cancer testis antigen, LY6K, which is located on chromosome 8q24.3. METHODS: Five BC cell lines were subjected to high-resolution array-comparative genomic hybridisation with 244000 probes. The expression levels of LY6K mRNA were evaluated in BC cell lines and clinical BC specimens by real-time reverse transcription-PCR. The cell lines were subjected to fluorescence in situ hybridisation of LY6K. Cell viability was evaluated by cell growth, wound healing, and matrigel invasion assays.

RESULTS: Typical gained loci $(P<0.000 \mid)$ at 6p2|.33-p2|.32, 8q24.3, 9q34.|3, | |q|3.|-q|4.|, |2q|3.|2-q|3.|3, |6p|3.3, and $20 \mathrm{q} 1 \mathrm{l} .2 \mathrm{I}-\mathrm{q} 13.33$ were observed in all of the cell lines. We focused on 8q24.3 locus where LY6K gene harbours, and it was the top upregulated one in the gene profile from the BC cell line. LY6K mRNA expression was significantly higher in 91 BCs than in 37 normal bladder epitheliums $(P<0.000 \mathrm{I})$. Fluorescence in situ hybridisation validated that the high LY6K mRNA expression was due to gene amplification in the region where the gene harbours. Cell viability assays demonstrated that significant inhibitions of cell growth, migration, and invasion occured in LY6K knock down BC cell lines; converse phenomena were observed in a stable LY6K transfectant; and LY6K knockdown of the transfectant retrieved the original phenotype from the LY6K transfectant.

CONCLUSION: Upregulation of the oncogenic LY6K gene located on the gained locus at 8q24.3 may contribute BC development. British Journal of Cancer (201 I) I 04, 376-386. doi:I0.1038/sj.bjc.6605990 www.bjcancer.com

Published online 9 November 2010

(c) 201 I Cancer Research UK

Keywords: LY6K; bladder cancer; array-CGH; 8q24.3

Bladder cancer (BC) is among the five most common malignancies worldwide, and it is the second most common tumour of the genitourinary tract and the second most common cause of death in patients with genitourinary tract malignancies (Jemal et al, 2009). In Japan, the age-standardised mortality rate of $\mathrm{BC}$ patients has increased slightly since 1993 (Qiu et al, 2009). The 5-year survival rate of patients with non-muscle-invasive $\mathrm{BC}$ is close to $90 \%$, whereas that with muscle-invasive $\mathrm{BC}$ is $\sim 60 \%$. In spite of various therapeutic treatments, more than $90 \%$ of patients with metastasis die within the first 5 years (Luke et al, 2009). Therefore, new diagnostic methods and new treatments for BC are urgently needed.

Comparative genomic hybridisation (CGH) has facilitated chromosomal characterisation of solid tumours, as it can provide detailed information on gain and loss of tumour DNA across the entire genome (Inazawa et al, 2004; Ishkanian et al, 2004). Conventional CGH is widely used to analyse many types of tumours, including BC (Hovey et al, 1998; Zhao et al, 1999; Simon et al, 2000; von Knobloch et al, 2000; Mahdy et al, 2001). Recently, microarray-based CGH has been used by several groups to study copy number instability and aberration type in BC specimens (Stoehr et al, 2004; Blaveri et al, 2005; Shinoda et al, 2007; Yamamoto et al, 2007; Hurst et al, 2008). According to the previous $\mathrm{BC}$ studies, frequent copy number gains

*Correspondence: Associate Professor H Enokida;

E-mail: enokida@m.kufm.kagoshima-u.ac.jp

Received 12 July 2010; revised 7 October 2010; accepted 18 October 2010; published online 9 November 2010 have been observed at 1q, 3p, 3q, 5p, 6p, 8q, 10p, 11q, 12q, 17q, 19q, and $20 \mathrm{q}$, whereas copy number losses have been observed at $2 \mathrm{q}, 4 \mathrm{q}$, $5 q, 8 p, 9 p, 9 q, 10 q, 11 p, 11 q, 13 q$, and 18q. These studies also demonstrated that the aberration patterns characterise invasive or non-invasive BC (Hovey et al, 1998; Zhao et al, 1999; Simon et al, 2000; Mahdy et al, 2001; Shinoda et al, 2007; Blaveri et al, 2009), and that they could be progression markers for BC (von Knobloch et al, 2000; Stoehr et al, 2004; Yamamoto et al, 2007). Their findings suggest that promising candidates for tumour-related genes might be located where the aberrations occur. However, identification of tumourrelated genes is difficult because many genes are involved in the larger chromosomal areas.

Gene expression profiling by oligonucleotide microarray analysis is an excellent tool for screening candidate genes that have a tumour suppressive or oncogenic function in BC (Dyrskjot et al, 2003; Kawakami et al, 2006). We previously found by microarray analysis that SKP2 and CKS1 contribute to progression and prognosis in BC (Kawakami et al, 2007). However, the hundreds of candidate genes identified by microarray analysis can make it difficult for investigators to decide which genes to study. Expression analysis of genes located in regions of gains or losses has shown that the gene expression level changes along with the gene copy number (Inazawa et al, 2004; Ishkanian et al, 2004). For example, comparisons of arrayCGH and transcriptome data have shown that $40-60 \%$ of the genes in highly amplified regions are actually overexpressed (Pollack et al, 2002; Heidenblad et al, 2005). Therefore, genome amplifications and homozygous deletions could be landmarks in cancer cell genomes for 
identifying oncogenes and tumour suppressor genes, respectively. Our group previously integrated array-CGH data analysis with gene expression profiling to identify candidate genes with oncogenic function in squamous cell carcinoma (Sugimoto et al, 2009). We have now used high-resolution array-CGH, performed using about 244000 probes with a length of 60 -mer. This proved to be a powerful profiling tool because it detected more deletions and smaller regions of gains.

$L Y 6 K$, which is located at $8 \mathrm{q} 24.3$, belongs to the $L Y 6$ family. It shows high homology to the low-molecular-weight glycosylphosphatidyl-inositol-anchored molecule, which is either a cell surface receptor or a secreted granule involved in the cell signaling pathway (de Nooij-van Dalen et al, 2003). It is also a cancer/testis antigen, that is, a protein highly expressed in cancer cells but not in normal cells, except for testis (Scanlan et al, 2004; Ishikawa et al, 2007; Kono et al, 2009). Several groups have shown elevated expression of $L Y 6 \mathrm{~K}$ mRNA in human head and neck squamous cell carcinomas and in lung, oesophageal, and breast cancers (de Nooij-van Dalen et al, 2003; Lee et al, 2006; Ishikawa et al, 2007). However, little is known about the functional role of LY6K in BC development. We evaluated LY6K mRNA expression levels in clinical BC samples and established a stable $L Y 6 K$ transfectant for functional analysis of the gene.

\section{MATERIALS AND METHODS}

\section{Cell lines and culture}

We used five human BC cell lines: BOY was established in our laboratory from an Asian male patient aged 66 diagnosed with stage III BC with lung metastasis (Takemoto et al, 1997); T24, UMUC, and J82 were obtained from the American Type Culture Collection; and KK47 was established at Kanazawa University (Imao et al, 1999) and kindly provided. These cell lines were maintained in a minimum essential medium (Sigma-Aldrich, St Louis, MO, USA) supplemented with $10 \%$ fetal bovine serum (FBS; Equitech-Bio Inc., Kerrville, TX, USA) in a humidified atmosphere of $5 \% \mathrm{CO}_{2}$ and $95 \%$ air at $37^{\circ} \mathrm{C}$.

\section{Array-CGH analysis of $\mathrm{BC}$ cell lines}

Chromosomal DNA was isolated from the five cell lines using a FlexiGene (Qiagen, Hilden, Germany) in accordance with the manufacturer's protocol. The purity and molecular weight of the DNA were estimated using agarose gels. The Human Genome CGH Microarray $244 \mathrm{~K}$ (Agilent Technologies, Palo Alto, CA, USA), which contains over 244000 60-mer oligonucleotide probes, spanning coding and non-coding genomic sequences with median spacing of 7.4 and $16.5 \mathrm{~kb}$, respectively, was used for copy number measurement. Human genomic DNA (Novagen, Madison, WI, USA) was used as a reference. Labelling, hybridisation, and scanning were performed in accordance with the manufacturer's protocol. Common aberrant loci were detected using CGH Analytics Software (Agilent Technologies) with the ADM2 algorithm ( $\mid \log 2$ ratio $\mid>0.3, P$-value $<0.05$, overlap $<0.5$; de Smith et al, 2007). The array-CGH data from this study have been submitted to the NCBI Gene Expression Omnibus (GEO; http:// www.ncbi.nlm.nih.gov/geo) under accession no. GSE19714.

\section{Oligonucleotide microarray analysis of $\mathrm{BC}$ cell lines}

Total RNA was extracted using TRIzol reagent (Invitrogen, Carlsbad, CA, USA) in accordance with the manufacturer's protocol. The integrity of the RNA was checked by a RNA 6000 Nano Assay kit and a 2100 Bioanalyzer (Agilent Technologies). The Whole Human Genome Microarray 44K (no. G4112F, Agilent Technologies), which contains over 41000 60-mer oligonucleotide probes (GEO platform ID: GPL4133), was used for expression profiling. Hybridisation and washing were performed in accordance
Table I Patient characteristics

\begin{tabular}{lc}
\hline Bladder cancer & 91 \\
Total number & $74(46-100)$ years \\
Median age (range) & 20 \\
Stage & 27 \\
PTa & 20 \\
PT1 & 6 \\
PT2 & 4 \\
PT3 & 14 \\
PT4 & \\
Unknown & 7 \\
Grade & 41 \\
G1 & 31 \\
G2 & 12 \\
G3 & \\
Unknown & \\
Normal bladder epithelium & 37 \\
Total number & $68(32-77)$ years \\
Median age (range)
\end{tabular}

with the instructions of the manufacturer. Because no normal bladder epithelium cell line is commercially available, we used human bladder total RNA (Clontech, Mountain View, CA, USA) as a reference for microarray analysis. The arrays were scanned using a Packard GSI Lumonics ScanArray 4000 (Perkin Elmer, Boston, MA, USA). The data obtained were analysed by means of DNASIS array software (Hitachi Software Engineering, Yokohama, Japan), which converted the signal intensity for each spot into text format. The data from each microarray study were normalised using glucuronidase- $\beta$ (GUSB) and expressed in absolute numbers. The oligonucleotide array data are available for reference (NCBI GEO; http://www.ncbi.nlm.nih.gov/geo; under accession no. GSE19716).

\section{Clinical samples}

In all, 91 tissue samples were obtained from BC patients who had undergone surgical resection at our institution between 2003 and 2007. Also used were 37 pathologically proven normal bladder epithelium (NBE) samples derived from organ-confined prostate cancer patients who underwent prostatectomy. The background and clinicopathological characteristics of the patients are summarised in Table 1 . These 128 samples were used for quantitative real-time reverse transcription PCR (RT-PCR). They were staged in accordance with the American Joint Committee on Cancer Union Internationale Contre le Cancer tumour-node-metastasis classification and histologically graded (Sobin and Wittekind, 2002). Our study was approved by the Bioethics Committee of Kagoshima University; written previous informed consent and approval were given by the patients.

\section{Sample preparation and total RNA extraction}

Freshly harvested tissues, immediately frozen in liquid nitrogen and stored at $-80^{\circ} \mathrm{C}$, were dissolved in TRIzol reagent (Invitrogen) for total RNA extraction following the protocol of the manufacturer. Total RNA from peripheral blood lymphocytes (PBLs) of BC patients were extracted by RNeasy Mini Kit (no. 74106, Qiagen). RNA density was measured with an Ultrospec 3100 Pro instrument (Amersham Biosciences, Piscataway, NJ, USA), and RNA quality was checked with the 2100 Bioanalyzer (Agilent Technologies).

\section{Complementary DNA (cDNA) preparation and quantitative real-time RT-PCR}

First strand cDNA with $1 \mu \mathrm{g}$ total RNA was synthesised using oligo-deoxythymidine primers of the RT system (Promega, Tokyo, Japan). Gene-specific PCR products were assayed continuously 
using a 7900 real-time PCR system (Applied Biosystems, Foster City, CA, USA) in accordance with manufacturer's protocol. The initial PCR step was a 10 -min hold at $95^{\circ} \mathrm{C}$. The cycles $(n=40)$ consisted of a 15 -s denaturation step at $95^{\circ} \mathrm{C}$, followed by $1 \mathrm{~min}$ annealing/extension at $63^{\circ} \mathrm{C}$. All reactions were performed in triplicate. For quantitative analysis, GUSB served as an internal control. The TaqMan probes and primers used for $L Y 6 K$ and GUSB were assay-on-demand gene expression products (Applied Biosystems). The gene expression relative to normal bladder RNA (human bladder total RNA, Clontech) was calculated using the comparative $C \mathrm{t}$ method.

\section{Fluorescence in situ hybridisation (FISH) analysis}

A FISH analysis of $L Y 6 K$ amplification was applied to five BC cell lines with $5-\mu \mathrm{M}$ thick paraffin-embedded tissues. For FISH probes, the $L Y 6 K$ locus-containing bacterial artificial chromosome probes (clone ID; RP11-119A16, RP11-163E23) and the chromosome 8 centromere probe (KBI-20008G, Kreatech Diagnosis, Amsterdam, The Netherlands) were labelled using a nick translation kit (Vysis 32-801300, Abbott Molecular Inc., Des Plaines, IL, USA) with orange-dUTP (Abbott molecular inc.) and PlatinumBright 495 (Kreatech Diagnosis), respectively. Denaturation, hybridisation, and post-hybridisation washing were carried out in accordance with Poseidon protocol (Kreatech Diagnosis). The specimens were counterstained with 4,6-dianidino-2-phenylindone (DAPI) and examined using a PM-2000 imaging system (HistoRx, New Haven, CT, USA) equipped with a triple filter set (Chroma, Bellows Falls, VT, USA): no. 41007 for orange-dUTP, no. 41017 for PlatinumBright 495, and no. 31000v2 for DAPI.

\section{Immunoblotting}

Total protein lysate was prepared with triple detergent lysis buffer composed of $50 \mathrm{~mm}$ tris- $\mathrm{HCl}(\mathrm{pH} 8.0), 150 \mathrm{~mm} \mathrm{NaCl}$, $0.02 \% \mathrm{NaN} 3,0.1 \%$ sodium dodecyl sulphate, $1 \% \mathrm{NP}-40$, and $0.5 \%$ sodium deoxycholate in the presence of a protease inhibitor cocktail (Sigma-Aldrich) and $100 \mathrm{~mm}$ phenylmethylsulfonyl fluoride. The protein lysate $(50 \mu \mathrm{g}$ per lane) was separated by NuPAGE electrophoresis on $4-12 \%$ bis-tris gel (Invitrogen) and transferred to a polyvinylidene difluoride membrane. Immunoblotting was carried out with diluted (1:500) polyclonal LY6K antibody (no. IMG_4183, Imgenex, San Diego, CA, USA). After being washed, the membrane was incubated with goat anti-rabbit IgG horseradish peroxidase conjugate (Bio-Rad, Hercules, CA, USA). Specific complexes were visualised with an Amersham ECL Western blotting detection system (GE Healthcare, Little Chalfont, UK).

\section{Small interfering RNA (siRNA) transfection}

We obtained siRNA oligonucleotide target to LY6K (small interfering (si)-LY6K) from the ON-TARGETplus SMART pool (L-013771-01-0005; Dharmacon, IL, USA) and non-target as control (si-control) from the non-targeting pool (D-001810-10-05; Dharmacon). The T24/LY6K transfectant, and two BC cell lines (BOY and KK47) were transfected with $10 \mathrm{~nm}$ siRNA using Lipofectamine RNAiMAX (Invitrogen) reagent following the manufacturer's protocol to evaluate the knockdown effect of siRNA by quantitative real-time RT - PCR and western blot analysis.

\section{Construction of LY6K expression vectors and transfection to T24 cells}

The LY6K vector was constructed by inserting full-length LY6K cDNA into the BamH I and Hind III restriction sites of the pBApo-CMV Neo vector (Takara Bio, Otsu, Japan). The LY6K and non-targeting (control) vectors were transfected into T24 cells by calcium phosphate co-precipitation. We did not subject UMUC, in which the LY6K expression level was lower than in T24, because its growth was too slow and it was not suitable for transfection. The T24/LY6K transfectants were split and grown in selective medium with $1000 \mathrm{mgl}^{-1}$ of G418. In all, 15 G418-resistant colonies were chosen and expanded in medium containing $200 \mathrm{mgl}^{-1}$ of G418. DNA sequences for all constructs were confirmed by DNA sequencing (Bio Matrix Research Inc., Tokyo, Japan). Finally, we selected the one with the highest LY6K mRNA expression among the clones.

\section{XTT assays}

Cells were seeded at a density of $3 \times 10^{3}$ cells per well in 96-well plates and incubated for $48 \mathrm{~h}$. Subsequently, cell viability was determined by the XTT assay following the manufacturer's protocol (Roche Applied Sciences, Indianapolis, IN, USA). The plates were read using an MPR-A4i microplate reader (Tosho, Tokyo, Japan). All experiments were repeated in triplicate.

\section{Wound healing assay}

Cells $\left(2 \times 10^{5}\right)$ were seeded into six-well plates and cultured in medium containing $10 \%$ of FBS to create a confluent monolayer. They were carefully wounded using $200-\mu$ l pipette tips and any cell debris was removed with phosphate-buffered saline. Microphotographs were taken, and quantitative analysis of the percentage of wound healing was calculated using the distance across the wound at $0 \mathrm{~h}$ and the indicated time for each cell lines. All experiments were repeated in triplicate.

\section{Invasion assay}

In vitro invasion assay was done using $\mathrm{BD}$ BioCoat Matrigel Invasion Chambers (BD Biosciences, Bedford, MA, USA) in 24-well plates. Cancer cells $\left(5 \times 10^{4}\right)$ were added to the upper chamber, and the lower chamber was filled with conditioned medium. After being incubated for $24 \mathrm{~h}$, cells that migrated through the membrane to the lower surface were stained with Giemsa solution. Four randomly selected $\times 200$ magnification fields were photographed, and the number of invading cells was counted. All experiments were repeated in duplicate.

\section{Statistical analysis}

The relationship between two groups of findings and numerical values obtained by real-time PCR and other assay was analysed with the Mann - Whitney $U$-test. The analysis software was Expert StatView (version 4, SAS Institute Inc., Cary, NC, USA); the box plot style with logarithmic scale was constructed, and the nonadjusted statistical level of significance of $P$-value was $<0.05$. The $95 \%$ confidence interval (CI) was calculated using Microsoft Office Excel (version 2007, Microsoft Corp., Redmond, WA, USA).

\section{RESULTS}

\section{Genomic profiling of BC cell lines by array-CGH}

To produce a comprehensive survey of genomic aberrations in $\mathrm{BC}$, five $\mathrm{BC}$ cell lines were analysed using array-CGH for patterns of chromosomal gains and/or losses. Predominantly gained loci were observed at the several loci (Figure 1A, and Supplementary Table SI). Among the gained loci, significant gains $(P<0.001)$ at 6p21.33-p21.32, 8q24.3, 9q34.13, 11q13.1-q14.1, 12q13.12-q13.13, $16 \mathrm{p} 13.3$, and 20q11.21-q13.33 were observed in all of the cell lines (100\%; Table 2$)$. On the other hand, lost loci were commonly found at $4 \mathrm{p}, 4 \mathrm{q}, 10 \mathrm{p}, 19 \mathrm{p}$, and $21 \mathrm{q}$ in all cell lines (100\%; Figure $1 \mathrm{~A}$, and Supplementary Table SII). We focused on the gain locus at $8 \mathrm{q} 24.3$ that was one of the most frequent event in the cell 
A

Chromosomes

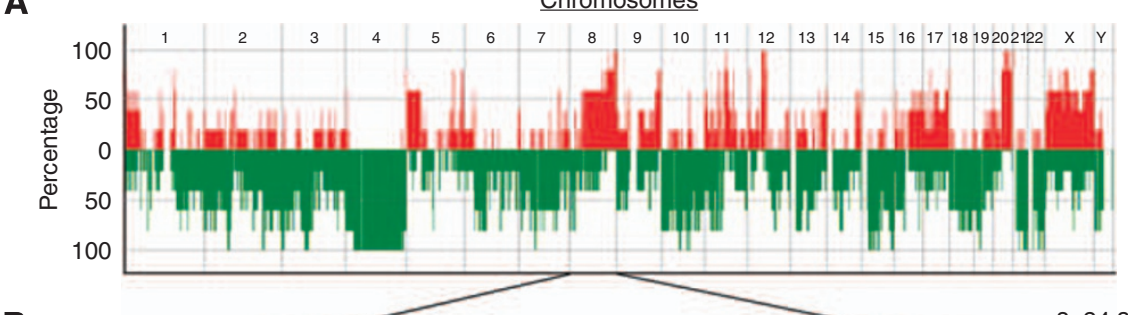

B
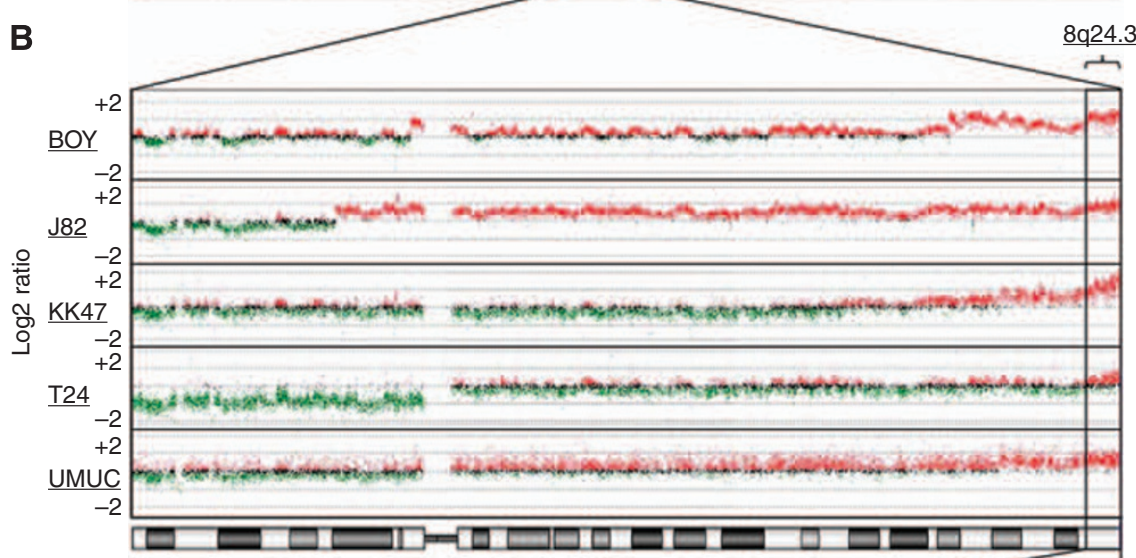

C

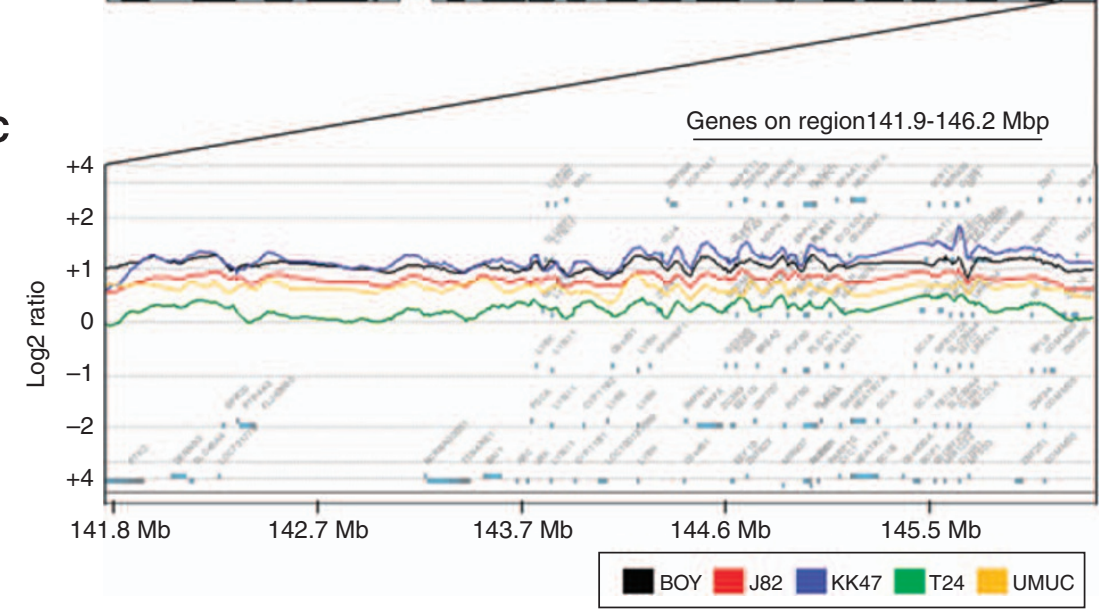

Figure I (A) Array-CGH profiling of five BC cell lines showing recurrence of chromosomal alterations. Integer value recurrence of copy number alterations in segmented data ( $y$-axis) was plotted for each probe aligned along the $x$-axis in chromosome order. Red and green bars denote gain and loss of chromosome material, respectively. The most recurrent regions of DNA copy number gains were on chromosomes Iq, 8q, I lq, and 20q, whereas recurrent regions of copy number loss were on chromosomes 4p, 4q, 10p, 19p, and 21 q. (B) Magnification of chromosome 8 locus in array-CGH profiling. Red and green denote $>0.5$ and $<0.5$ of log2 ratio value. The predominant aberration occurred at 8q24.3. (C) Smoothed copy number profile from 143.2 to 1 $45.6 \mathrm{Mb}$ on chromosome 8 (8q24.3) using CGH Analytics Software (Agilent Technologies). A total of 9| genes were located on this region, and LY6K was located at $143.8 \mathrm{Mb}$. Among the genes, 56 were upregulated more than two-fold compared with the reference RNA in the BC cell lines (Table 3).

lines (Figure 1B, and Table 2), because it has not been studied in detail for $\mathrm{BC}$. Figure $1 \mathrm{C}$ demonstrated that the log ratio of $141.9-146.2 \mathrm{Mb}$ on chromosome 8 (8q24.3) was robustly high in each cell line.

\section{Genomic copy number and expression profile data at $8 \mathrm{q} 24.3$}

To identify the genes involved in BC development, we evaluated the expression levels of 91 genes located at 8q24.3 for the five BC cell lines using an oligo-microarray. We identified 56 genes that were upregulated more than two-fold in comparison with the reference RNA (Table 3 upper). The LY6K gene was the top upregulated one in the gene profile from the $\mathrm{BC}$ cell line with a fold change of 28.62 (relative to normal bladder; Table 3). Hence, we focused on $L Y 6 K$ being a promising candidate gene for oncogenic function in BC development. We found that eight LY6 family genes were located on the region between 141.9 and $146.2 \mathrm{Mb}$ on chromosome 8 (8q24.3; Figure 1C). The expression levels of $L Y 6 E$, $G M L$, and $L Y P D 2$ were relatively upregulated with an average fold of 6.37, 3.67, and 1.34, whereas those of $L Y N X 1, L Y 6 H$, and $L Y 6 D$ were not upregulated in the cell lines (Table 3, bottom).

\section{Evaluation of $L Y 6 K \mathrm{KRNA}$ expression and the gene amplification in BC cell lines, and clinical BC samples}

Real-time RT-PCR revealed that the expression levels of $L Y 6 K$ mRNA were commonly low in human normal tissues except for testis (Figure 2A). In human BC cell lines, $L Y 6 K$ mRNA expression was abundant in KK47 (184.9-fold relative to normal bladder), modest in BOY (43.6-fold), and weak in T24 (7.2-fold; Figure 2A). In clinical samples, $L Y 6 K$ mRNA expression was significantly higher in the $91 \mathrm{BC}$ samples than in the $37 \mathrm{NBE}$ samples (BC: mean $19.6 \pm 3.6$, 95\% CI 12.4-26.8; NBE $2.4 \pm 0.6$, 95\% CI 1.0-3.7; 
Table 2 Highly gained loci in BC cell lines

\begin{tabular}{|c|c|c|c|c|c|c|c|c|}
\hline \multirow[b]{2}{*}{ Chromosome } & \multirow[b]{2}{*}{ Arm } & \multicolumn{3}{|c|}{ Location } & \multirow[b]{2}{*}{ No. of probes } & \multirow[b]{2}{*}{$P$-value } & \multicolumn{2}{|c|}{ Cell lines with gained loci } \\
\hline & & Start & End & Size & & & No. & Name \\
\hline Chrl & p36.13 & 16443872 & 16570594 & 126723 & 18 & 0.0052 & 4 & J82, T24, KK47, BOY \\
\hline Chrl & p36.1 I & 26486288 & 26582083 & 95796 & 15 & 0.0055 & 4 & T24, BOY, KK47, J82 \\
\hline Chr5 & q35.3 & $1790480 \mid 4$ & $179 \mid 82725$ & 134712 & 18 & 0.0025 & 4 & BOY, KK47, T24, UMUC \\
\hline Chr6 & p22.1 & 29854670 & 29923588 & 68919 & 9 & 0.0075 & 4 & UMUC, BOY, KK47, J82 \\
\hline Chr6 & p21.33-p21.32 & 32450499 & 32450899 & 401 & । & 0.0012 & 5 & KK47, UMUC, T24, BOY, J82 \\
\hline Chr8 & $q \mid 3.1$ & 66942022 & 67492376 & 550355 & 52 & 0.0024 & 4 & T24, BOY, UMUC, J82 \\
\hline Chr8 & q23.3-q24.3 & | 15977013 & 146294242 & 30317230 & 2404 & 0.0009 & 4 & UMUC, J82, KK47, BOY \\
\hline Chr8 & $\mathrm{q} 24.3$ & 141934794 & $146|5| 558$ & 4216765 & 496 & 0.0019 & 5 & T24, UMUC, J82, BOY, KK47 \\
\hline Chr9 & p|3.3-p|3.2 & $35863 \mid 45$ & 36917314 & $1054 \mid 70$ & 105 & 0.0030 & 4 & J82, KK47, UMUC, T24 \\
\hline Chr9 & q32 & | 16756726 & | 17059739 & 303014 & 45 & 0.0052 & 4 & BOY, KK47, T24, J82 \\
\hline Chr9 & q33.3-q34.3 & 129659306 & 140696609 & | | 037304 & 1379 & 0.0074 & 4 & BOY, T24, J82, KK47 \\
\hline Chr9 & $q 34.13$ & 134348656 & 135612832 & | 264 | 77 & 145 & 0.0069 & 5 & UMUC, BOY, T24, J82, KK47 \\
\hline Chrll & pl3 & 33673844 & 33768828 & 94985 & 13 & 0.0083 & 4 & KK47, J82, UMUC, BOY \\
\hline Chrll & $q \mid 3.1$ & 65200770 & 65338587 & 137818 & 18 & 0.0011 & 5 & UMUC, BOY, J82, T24, KK47 \\
\hline Chrll & $q|3.2-q| 3.4$ & 66619419 & 74488807 & 7869389 & 807 & 0.0012 & 5 & BOY, J82, T24, KK47, UMUC \\
\hline Chrll & $q|3.3-q| 4 . \mid$ & 70270969 & 78189879 & 7918911 & 847 & 0.0050 & 5 & BOY, J82, T24, UMUC, KK47 \\
\hline Chrl2 & $q|3.1|-q \mid 3.2$ & 46756675 & 56434303 & 9677629 & 1216 & 0.0013 & 4 & T24, UMUC, BOY, KK47 \\
\hline Chrl2 & $q 13.12$ & 50421056 & 50642687 & 221632 & 30 & 0.0078 & 5 & J82, UMUC, T24, KK47, BOY \\
\hline Chrl2 & $q 13.13$ & 53661113 & 53814590 & 153478 & 25 & 0.0087 & 5 & J82, UMUC, T24, KK47, BOY \\
\hline Chrl6 & pl3.3 & 2880932 & 2923782 & 42851 & 10 & 0.0051 & 5 & BOY, T24, J82, KK47, UMUC \\
\hline Chrl7 & $\mathrm{q} 25.2$ & 74890765 & 74958581 & 67817 & 7 & 0.0088 & 4 & KK47, J82, T24, BOY \\
\hline Chr20 & $q|1.21-q| 3.33$ & 29833409 & 62908815 & 33075407 & 3101 & 0.0027 & 5 & BOY, UMUC, KK47, T24, J82 \\
\hline ChrX & p22.2-p22.12 & 16205283 & 20103495 & 3898213 & 377 & 0.0070 & 4 & UMUC, J82, BOY, KK47 \\
\hline ChrX & $q 11.1-q 28$ & 62707611 & 152734906 & 90027296 & 6184 & 0.0061 & 4 & KK47, UMUC, J82, BOY \\
\hline
\end{tabular}

Abbreviations: $\mathrm{BC}=$ bladder cancer; $\mathrm{Chr}=$ chromosome.

$P<0.0001$; Figure 2B). When we used a cut-off value of 3.7, which was the upper limit of $95 \%$ CI for NBEs, 62 of 91 BCs $(68 \%)$ were determined to be samples with high LY6K mRNA expression. The expression levels of LY6K mRNA in (PBLs of BC patients $(n=4)$ were extremely low compared with those of BCs and NBEs, indicating that PBL contamination does not increase the level of LY6K mRNA expression in BC tissues. We found no relationship between the LY6K mRNA expression and clinicopathological parameters (tumour stage, and grade). To investigate whether high $L Y 6 K$ mRNA expression depends on gene amplification at the gene location, we performed FISH. The gene amplification of $L Y 6 K$ (red signal) in comparison with that of the control centromere probe (green signal) was higher in BOY and KK47 and lower in T24 (Figures $3 \mathrm{~A}-\mathrm{C}$ ). These results corresponded with the LY6K mRNA expression levels in these cell lines (Figure 2A).

\section{Effects of LY6K knockdown on cell growth, migration and invasion}

For loss-of-function studies, we used BOY and KK47, in which the LY6K mRNA was markedly expressed (Figure 2A). Real-time RT-PCR and immunoblotting demonstrated that LY6K mRNA expression was substantially lower after si- $L Y 6 K$ transfection to BOY and KK47 (Figure 4A). After 48-h si-LY6K transfection to each cell line, XTT assay revealed significant decreases in cell growth in si- $L Y 6 K$ transfectants in comparison with si-control transfectants (BOY, $74.1 \pm 0.9 \%$ and $100 \pm 0.6 \%$, respectively, $P=0.0039$; and KK47, $88.2 \pm 1.5 \%$ and $100 \pm 6.5 \%$, respectively, $P=0.0163$; Figure 4B). We found no cytotoxic effect of the transfection reagent in the transfectants compared with the wild types. We subjected BOY to wound healing assay, which can evaluate both cell migration and cell proliferation activity, and matrigel invasion assay. We did not use KK47 because it was not suitable for the experiments because of its focal growth pattern. Wound healing assays demonstrated that the migration into the wound area was slower in the si-LY6K-transfected BOY than in the si-control-transfected BOY $(54.9 \pm 3.6 \%$ and $100 \%$, respectively, $P<0.0001$; Figure 4C). Matrigel invasion assay showed that the number of cells invading through the membrane was significantly lower in the si-LY6K-transfected BOY than in the si-controltransfected BOY $(21.5 \pm 5.5 \%$ and $100 \pm 14.8 \%$, respectively, $P=0.0016$, Figure 4D).

\section{Effects of LY6K overexpression on cell growth, migration, and invasion}

Because T24 showed a lower expression of $L Y 6 K$ mRNA relative to other cell lines (Figure 2A), we established a stable T24/LY6K transfectant for gain of function studies. Real-time RT-PCR showed a high expression level of $L Y 6 K$ mRNA in the transfectant, whereas it was weak in the T24/non-targeting vector transfectant (control; Figure 5A). Immunoblotting demonstrated a high expression of $17-\mathrm{kDa}$ LY6K protein in the transfectant, whereas it was undetectable in the control (Figure 5A). Three independent XTT assays consistently demonstrated significant acceleration of cell growth in the transfectant compared with the control (162.1 \pm $1.1 \%$ and $100 \pm 1.3 \%$, respectively, $P=0.0039$; Figure $5 \mathrm{~B}$ ). Wound healing assays demonstrated that the transfectant migrated into the wound area more rapidly than the control $(163.4 \pm 0 \%$ and $100 \pm 4.4 \%$, respectively, $P=0.0003$; Figure $5 \mathrm{C}$ ). Matrigel invasion assay showed that the number of cells invading through the membrane was significantly higher in the transfectant than in the control $(228.3 \pm 23.4 \%$ and $100 \pm 11.3 \%$, respectively, $P=0.0209$; Figure 5D).

\section{Effects of LY6K knockdown in T24/LY6K transfectant on cell growth, migration, and invasion}

To investigate whether $L Y 6 K$ knockdown retrieves the original phenotype of T24 from that of the T24/LY6K transfectant, we transfected the transfectant with si-LY6K and subjected it to cell 
Table 3 Frequently upregulated genes on chromosome 8q24.3 in bladder cancer cell lines

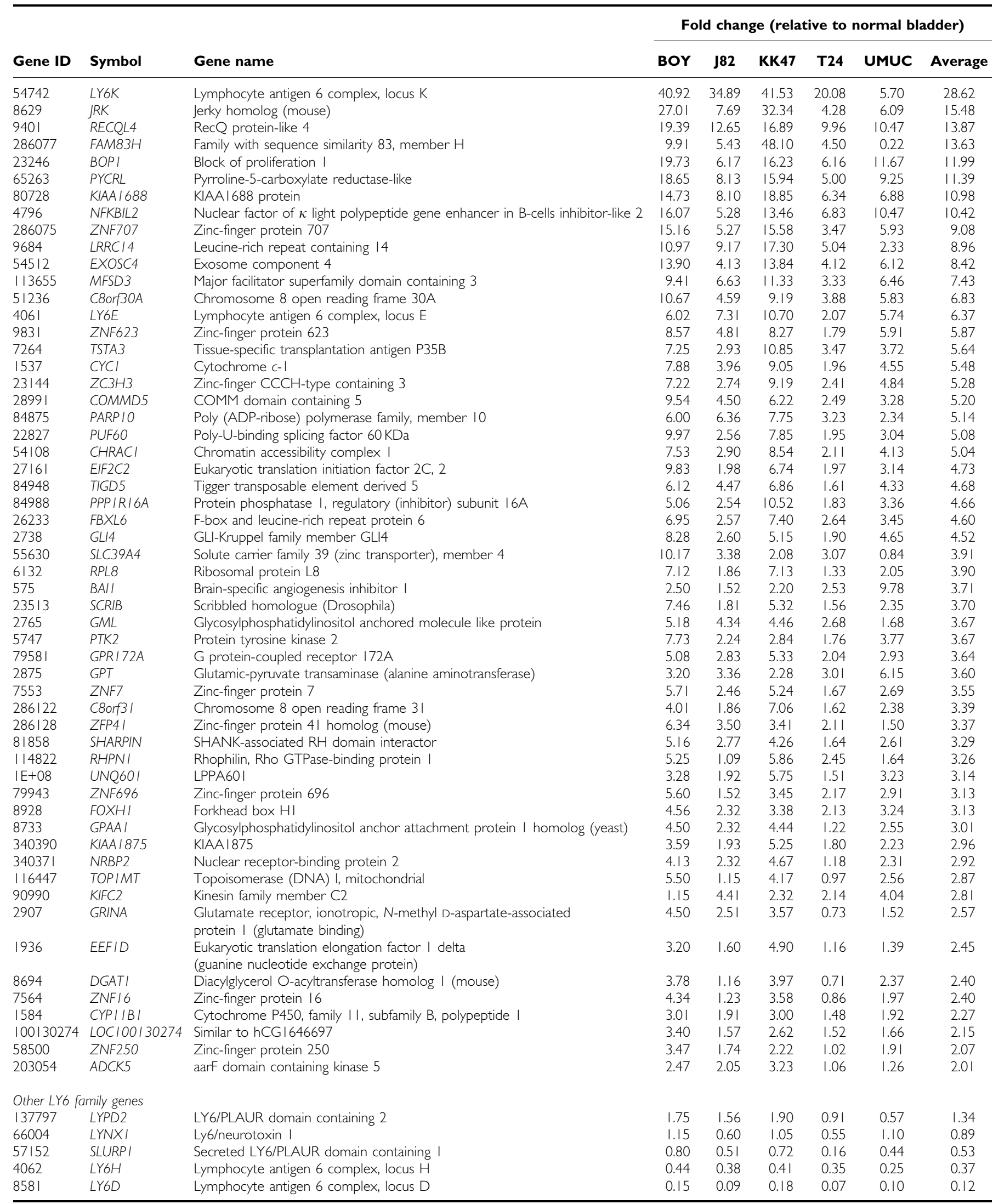





Figure 2 (A) LY6K mRNA expression levels in a panel of normal tissues and BC cell lines from real-time RT-PCR. Gene expressions relative to normal bladder were calculated using comparative Ct method. The expression levels were commonly low in human normal tissues except for testis; they were high in two BC cell lines (BOY and KK47). (B) LY6K mRNA expression was significantly higher in clinical BC samples than in normal bladder epithelium (NBE) samples. Expression levels of LY6K mRNA in peripheral blood lymphocytes (PBL) of BC patients $(n=4)$ were extremely low. The gene expressions were determined relative to average for NBE samples.

A

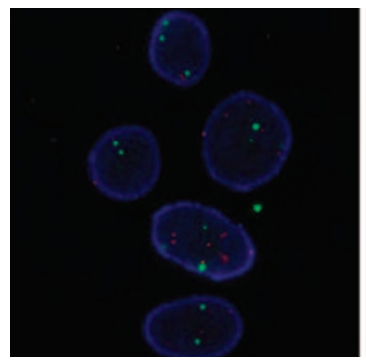

T24
B

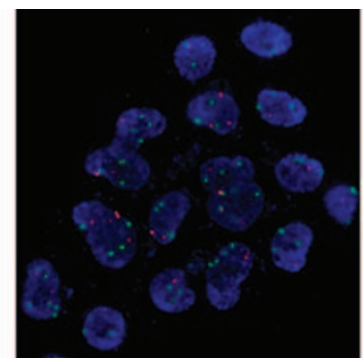

BOY
C

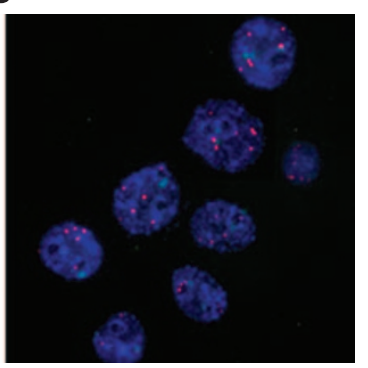

$\mathrm{KK} 47$

Figure 3 Examples of amplification of LY6K gene in BC. Copy number status of gene was determined by fluorescence in situ hybridisation (FISH) in (A) T24, (B) BOY, and (C) KK47 BC cell lines. Red signals were from LY6K gene probe, and green ones were from centrometric probe (magnification $\times 200)$.

viability studies. Real-time RT - PCR and immunoblotting demonstrated that LY6K expression was substantially lower after the si-LY6K transfection (Figure 6A). After 48 -h si-LY6K transfection of the transfectant, XTT assay revealed a significant decrease in cell growth in the si-LY6K transfectant compared with the si-control transfectant $(84.7 \pm 2.0 \%$ and $100 \pm 1.7 \%$, respectively, $P=0.0039$; Figure 6B). Wound healing assays demonstrated that the migration into the wound area was slower in the si-LY6K transfectant than in the si-control transfectant $(70.2 \pm 3.8 \%$ and $100 \%$, respectively, $P=0.0044$; Figure $6 \mathrm{C})$. Matrigel invasion assay showed that the number of cells invading through the membrane was significantly lower in the si-LY6K transfectant than in the si-control transfectant $(48.2 \pm 7.1 \%$ and $100 \pm 3.6 \%$, respectively, $P=0.0011 ;$ Figure 6D). 
A

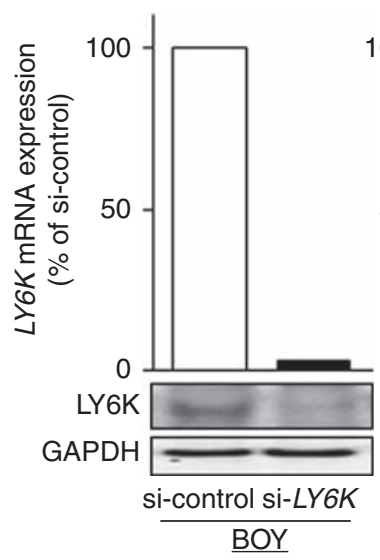

B

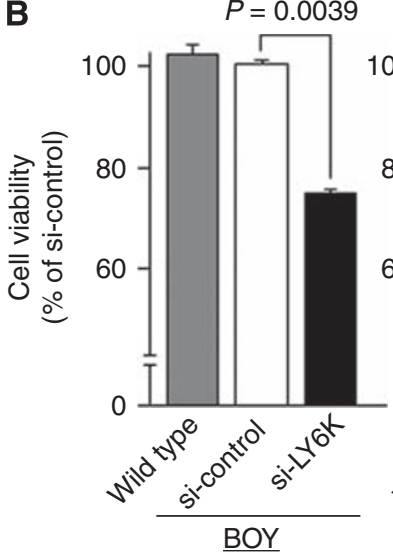

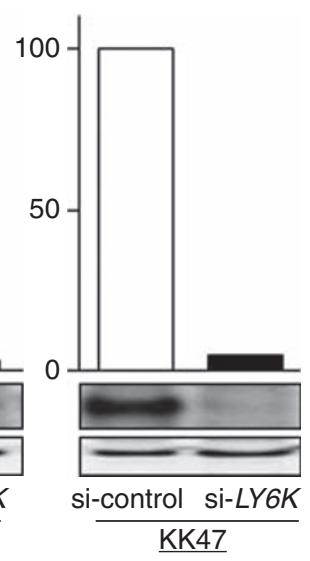

$P=0.0163$

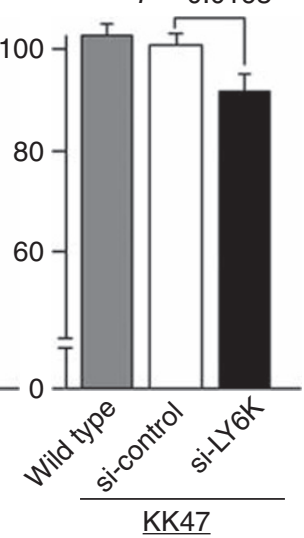

C

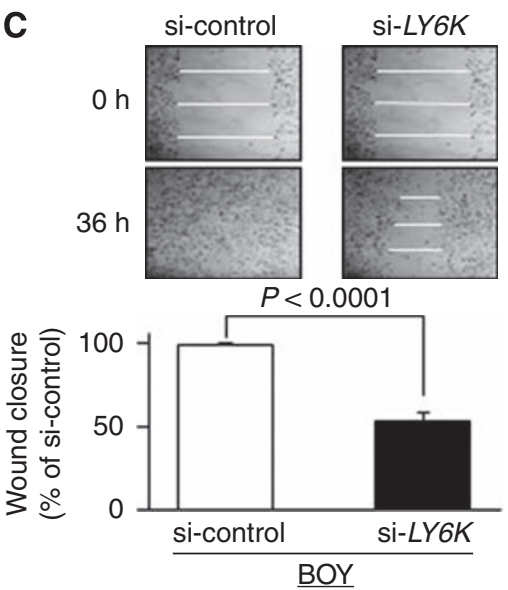

D


Figure 4 Effects of LY6K knockdown on cell growth. (A) LY6K mRNA expressions were markedly repressed in si-LY6K transfectants (BOY and KK47) in comparison with si-control transfectants. (B) Cell viability as determined by XTT assay. Greater growth inhibition was observed in the si-LY6K transfectants (BOY and KK47) than in the si-control transfectants. (C) Cell migration activity revealed by the wound healing assay. Greater inhibition of cell migration was observed in si-LY6K transfectant (BOY) than in the si-control transfectant. (D) Cell invasion activity by matrigel invasion assay. The number of cells invading through the membrane was significantly lower in the si-LY6K transfectant (BOY) than in the si-control transfectant.

\section{DISCUSSION}

In previous studies, chromosomal alteration analysis by CGH and gene expression profiling by microarray analysis have been investigated in various cancers (Inazawa et al, 2004; Ishkanian et al, 2004). Several oncogenes on the gained loci were identified in $\mathrm{BC}$ in the previous array-CGH studies; for example, CCND1, a member of cyclinD1, FGF3/4, fibroblast growth factors and $E M S 1$, a regulator of cell adhesion are located on 11q13 (Zaharieva et al, 2003); E2F3, a transcription factor positively regulating cell cycle, is located on 6p22 (Hurst et al, 2008); and KLK5, a serine protease involved in cancer progression, is located on 19q13.3 (Shinoda et al, 2007). However, the large number of candidate genes identified by array-CGH analysis can make it difficult for researchers to identify the crucial onco-related ones. Although differential gene expression demonstrated by microarray-defined probes can be related to numerical or structural chromosomal alterations, it is unclear if such changes are also clustered in distinct chromosomes or genomic regions and whether chromosomal alterations always reflect gene expression changes. To address this issue, we used a high-resolution array containing about 244000 probes, which enabled exhaustive detection of chromosomal gain or loss with a median spacing of $7.4 \mathrm{~kb}$ of cording regions. We found chromosomal copy number gains on chromosome arms $6 \mathrm{p}, 8 \mathrm{q}, 9 \mathrm{q}, 11 \mathrm{q}, 12 \mathrm{q}, 16 \mathrm{p}$, and $20 \mathrm{q}$ and losses on chromosome arms $4 \mathrm{p}, 4 \mathrm{q}, 10 \mathrm{p}, 19 \mathrm{p}$, and $21 \mathrm{q}$ in the five $\mathrm{BC}$ cell lines. Many regions showing copy number alteration matched those identified in the previous BC studies. We combined arrayCGH data with mRNA expression data from oligo-microarray data analysis using five BC cell lines and 14 clinical BC samples (Kawakami et al, 2006). By using three different genome-wide screenings in $\mathrm{BC}$, we readily identified a new target gene, $L Y 6 \mathrm{~K}$, located at 8q24.3, which has not been identified in array-CGH research of BC. We found marked copy number gains in most of the chromosome 8q24.3 region. Several oncogenes including $M Y C$, $P V T 1, D D E F 1, P T K 2, G M L$, and BOP1 are located on this region, where the LY6K gene is closely located (Mahdy et al, 2001; Saramäki et al, 2006). Our profile showed that these oncogenes were upregulated more than two-fold in the BC cell lines (Table 3). These results suggest that the copy number gain of chromosome $8 \mathrm{q} 24.3$ has an important role in cancer development through overexpression of the oncogenes encoded in the region. Thus, gene profiling based on our multiple genome-wide screening enable the use of strategies for finding novel oncogenes in human BC.

Several investigations found overexpression of LY6K in several human malignancies, such as head and neck squamous cell carcinomas and breast, lung, and oesophageal cancers (de Nooijvan Dalen et al, 2003; Scanlan et al, 2004; Lee et al, 2006; Ishikawa et al, 2007; Choi et al, 2009; Kono et al, 2009). LY6K overexpression is associated with poorer prognosis for patients with non-small cell lung carcinomas as well as oesophageal squamous cell carcinomas (Ishikawa et al, 2007). The migration activity was significantly higher in $L Y 6 K$-transfected breast cancer cell lines (Choi et al, 2009). We established a permanent LY6K-transfected 
A



B

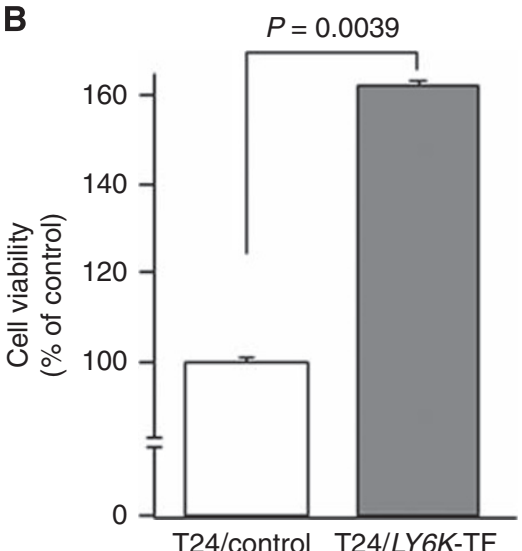

C
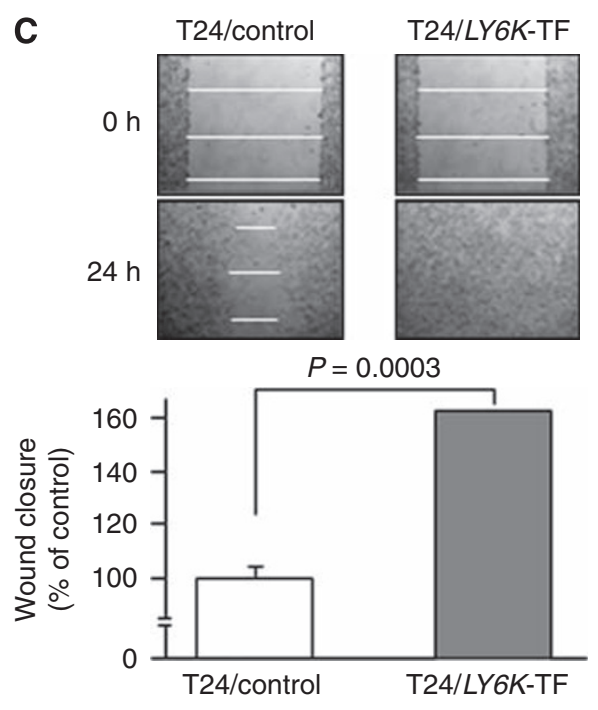

D

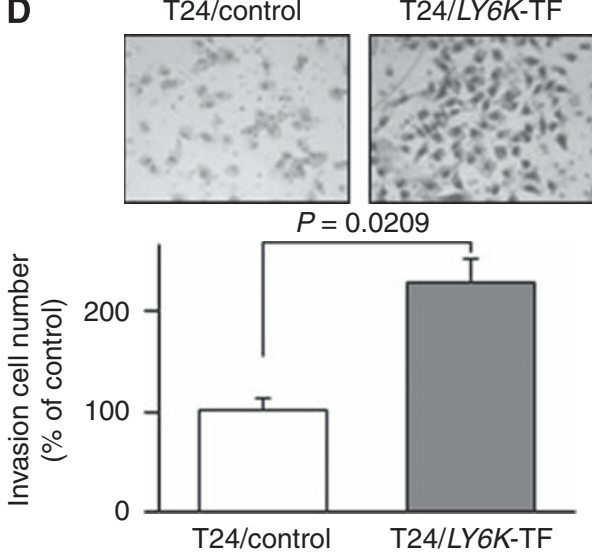

Figure 5 Effects of LY6K overexpression on cell growth, migration, and invasion. (A) LY6K mRNA and protein expressions in the T24/LY6K transfectant (TF) and T24/non-targeting vector transfectant (control). The expression levels of LY6K were markedly higher in the T24/LY6K-TF than in the control. (B) Cell viability as determined by XTT assay. A significant acceleration of cell growth was observed in the T24/LY6K-TF in comparison with the control. (C) Cell migration activity by the wound healing assay. Greater acceleration of cell migration was observed in the T24/LY6K-TF than in the control. (D) Cell invasion activity by matrigel invasion assay. The number of cells invading through the membrane was significantly higher in the T24/LY6K-TF than in the control.

$\mathrm{BC}$ cell line and identified its persistent oncogenic functions including cell growth and invasion activity as well as its migration activity, all of which were retrieved by si-LY6K transfection. These findings suggest that LY6K functions as an oncogenic molecule and contributes to the development of various cancers. LY6K is also a cancer/testis antigen. A new immunotherapy using established cytotoxic T lymphocyte targeting LY6K was studied in lung and oesophageal cancer cell lines (Ishikawa et al, 2007; Kono et al, 2009), meaning that LY6K is a promising target for BC immunotherapy. The other members of the LY6 family genes are mostly located at 8q24.3 (LY6D, LY6E, LY6H, SLURP1, LYPD2, $L Y N X 1$, and $G M L)$. The functional roles of these genes are not completely understood. Previous studies demonstrated that LY6D is highly expressed in colorectal cancer (Reichling et al, 2005) and that also $L Y 6 E$ is in pancreatic cancer stem cells (Gou et al, 2007). $L Y 6 E$ and $G M L$ as well as $L Y 6 K$ were consistently among the top 40 upregulated genes in our profile. Thus, the LY6 family genes may have an oncogenic function in cooperation. However, our profile also showed that some of the LY6 family genes were not upregulated even though they are located on 8q24.3, wherein predominantly gained loci were located in the CGH array study. These results indicate that another epigenetic pathway might repress the mRNA expression of these genes. Further studies are necessary to elucidate whether LY6K expression in clinical specimen is actually regulated by the gained locus of 8q24.3.

The LY6 family members are assumed to have functions related to cell signalling and/or cell adhesion (de Nooij-van Dalen et al, 2003; Lee et al, 2006; Choi et al, 2009) although the precise role of LY6K in carcinogenesis is still unknown. To gain further insight into which genes are affected by $L Y 6 K$ gene expression, we performed gene expression analysis of the $L Y 6 K$ transfectant. The functional annotations of the upregulated genes after $L Y 6 K$ transfection were distributed among nine categories including cell cycle, transcription, and signal transduction. Several clusters of genes in our profile are oncogenic molecules contributing to cancer development, for example, E2F genes (Hurst et al, 2008), insulin-like growth factors (Huszar et al, 2009), cell division cycle genes (Chen et al, 2006), $\alpha-/ \beta$ tubulines (Canta et al, 2009), and zinc finger proteins (Gommans et al, 2005; Supplementary Table SIII). These results suggest that LY6K promotes and activates cell-cycle-related genes in BC. Further investigation is necessary to test this hypothesis. In our cohort, there was no significant relationship between the LY6K mRNA expression and clinicopathological parameters. Regional epigenetic silencing and activation of multiple genes unrelated to chromosomal alterations may affect the pathological parameters of individual tumours. More precise studies with various experiments are needed to explain these phenomena. 

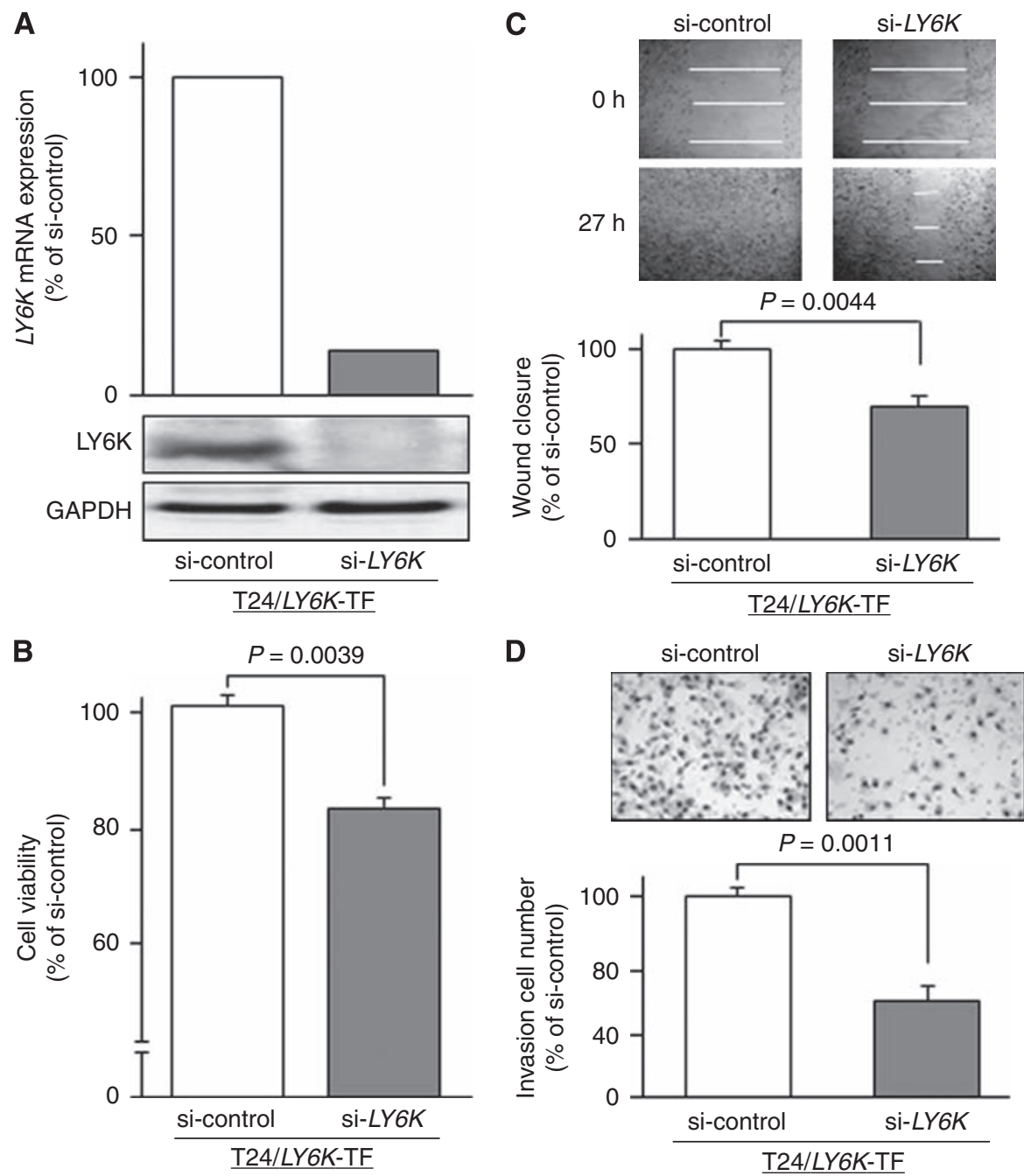

Figure 6 Effects of LY6K knockdown in T24/LY6K transfectant on cell growth, migration, and invasion. (A) LY6K mRNA expressions were markedly lower after si-LY6K-transfection of T24/LY6K transfectant (TF) than in the si-control transfectant. (B) Cell viability as determined by XTT assay. Significant growth inhibition was observed in the si-LY6K transfectant. (C) Cell migration activity by the wound healing assay. A significant inhibition of cell migration was observed in the si-LY6K transfectant. (D) Cell invasion activity by the matrigel invasion assay. The number of cells invading through the membrane was significantly decreased in the si-LY6K transfectant.

In summary, our studies firstly demonstrated that $L Y 6 K$ gene may have an oncogenic activity in human $\mathrm{BC}$ and chromosomal gain locus of 8q24.3 where $L Y 6 K$ gene harbours may have a critical role for BC development. We conducted experiments to clarify the gain and loss of functions using a stable $L Y 6 K$-transfected BC cell line and found that LY6K might have an oncogenic function, suggesting that it is a promising candidate for molecular targeting of human BC.

\section{REFERENCES}

Blaveri E, Brewer JL, Roydasgupta R, Fridlyand J, DeVries S, Koppie T, Pejavar S, Mehta K, Carroll P, Simko JP, Waldman FM (2005) Bladder cancer stage and outcome by array-based comparative genomic hybridization. Clin Cancer Res 11: 7012-7022

Canta A, Chiorazzi A, Cavaletti G (2009) Tublin: a target for antineoplastic drugs into the cancer cells but also in the peripheral nervous system. Curr Med Chem 16: 1315-1324

Chen JS, Lin SY, Tso WL, Yeh GC, Lee WS, Tseng H, Chen LC, Ho YS (2006) Checkpoint kinase 1-mediated phosphorylation of Cdc25C and bad proteins are involved in antitumor effects of loratadine-induced G2/M phase cell-cycle arrest and apoptosis. Mol Carcinog 45: $461-478$

\section{ACKNOWLEDGEMENTS}

We thank Ms M Miyazaki for her excellent laboratory assistance.

Supplementary Information accompanies the paper on British Journal of Cancer website (http://www.nature.com/bjc)

Choi SH, Kong HK, Park SY, Park JH (2009) Metastatic effect of LY-6K gene in breast cancer cells. Int J Oncol 35: 601-607

de Nooij-van Dalen AG, van Dongen GA, Smeets SJ, Nieuwenhuis EJ, Stigter-van Walsum M, SnoHw GB, Brakenhoff RH (2003) Characterization of the human Ly-6 antigens, the newly annotated member Ly-6K included, as molecular markers for head-and-neck squamous cell carcinoma. Int J Cancer 103: $768-774$

de Smith AJ, Tsalenko A, Sampas N, Scheffer A, Yamada NA, Tsang P, BenDor A, Yakhini Z, Ellis RJ, Bruhn L, Laderman S, Froguel P, Blakemore AL (2007) Array CGH analysis of copy number variation identifies 1284 new genes variant in healthy white males: implications for association studies of complex diseases. Hum Mol Genet 16: 2783-2794 
Dyrskjot L, Thykjaer T, Kruhoffer M, Jensen JL, Marcussen N, HamiltonDutoit S, Wolf H, Orntoft TF (2003) Identifying distinct classes of bladder carcinoma using microarrays. Nat Genet 33: 90-96

Gommans WM, Haisma HJ, Rots MG (2005) Engineering zinc finger protein transcription factors: the therapeutic relevance of switching endogenous gene expression on or off at command. J Mol Biol 354: 507-519

Gou S, Liu T, Wang C, Yin T, Li K, Yang M, Zhou J (2007) Establishment of clonal colony-forming assay for propagation of pancreatic cancer cells with stem cell properties. Pancreas 34: 429-435

Heidenblad $M$, Lindgren D, Veltman JA, Jonson T, Mahlamäki EH, Gorunova L, van Kessel AG, Schoenmakers EF, Höglund M (2005) Microarray analyses reveal strong influence of DNA copy number alterations on the transcriptional patterns in pancreatic cancer: implications for the interpretation of genomic amplifications. Oncogene 24: $1794-1801$

Hovey RM, Chu L, Balazs M, DeVries S, Moore D, Sauter G, Carroll PR, Waldman FM (1998) Genetic alterations in primary bladder cancers and their metastases. Cancer Res 58: 3555-3560

Hurst CD, Tomlinson DC, Williams SV, Platt FM, Knowles MA (2008) Inactivation of the $\mathrm{Rb}$ pathway and overexpression of both isoforms of E2F3 are obligate events in bladder tumours with 6p22 amplification. Oncogene 27: 2716-2727

Huszar D, Theoclitou ME, Skolnik J, Herbst R (2009) Kinesin motor proteins as targets for cancer therapy. Cancer Metastasis Rev 28 $197-208$

Imao T, Koshida K, Endo Y, Uchibayashi T, Sasaki T, Namiki M (1999) Dominant role of E-cadherin in the progression of bladder cancer. $J$ Urol 161: $692-698$

Inazawa J, Inoue J, Imoto I (2004) Comparative genomic hybridization (CGH)-arrays pave the way for identification of novel cancer-related genes. Cancer Sci 95: 559-563

Ishikawa N, Takano A, Yasui W, Inai K, Nishimura $\mathrm{H}$, Ito $\mathrm{H}$, Miyagi $\mathrm{Y}$, Nakayama H, Fujita M, Hosokawa $M$, Tsuchiya E, Kohno $N$, Nakamura Y, Daigo Y (2007) Cancer-testis antigen lymphocyte antigen 6 complex locus $\mathrm{K}$ is a serologic biomarker and a therapeutic target for lung and esophageal carcinomas. Cancer Res 67: 11601-11611

Ishkanian AS, Malloff CA, Watson SK, DeLeeuw RJ, Chi B, Coe BP, Snijders A, Albertson DG, Pinkel D, Marra MA, Ling V, MacAulay C, Lam WL (2004) A tiling resolution DNA microarray with complete coverage of the human genome. Nat Genet 36: 299-303

Jemal A, Siegel R, Ward E, Hao Y, Xu J, Thun MJ (2009) Cancer statistics, 2009. CA Cancer J Clin 59: 225-249

Kawakami K, Enokida H, Tachiwada T, Gotanda T, Tsuneyoshi K, Kubo H, Nishiyama K, Takiguchi M, Nakagawa M, Seki N (2006) Identification of differentially expressed genes in human bladder cancer through genomewide gene expression profiling. Oncol Rep 16: 521-531

Kawakami K, Enokida H, Tachiwada T, Nishiyama K, Seki N, Nakagawa M (2007) Increased SKP2 and CKS1 gene expression contributes to the progression of human urothelial carcinoma. J Urol 178: 301-307

Kono K, Mizukami Y, Daigo Y, Takano A, Masuda K, Yoshida K, Tsunoda T, Kawaguchi Y, Nakamura Y, Fujii H (2009) Vaccination with multiple peptides derived from novel cancer-testis antigens can induce specific T-cell responses and clinical responses in advanced esophageal cancer. Cancer Sci 100: $1502-1509$

Lee JW, Lee YS, Yoo KH, Lee KH, Park K, Ahn T, Ko C, Park JH (2006) LY-6K gene: a novel molecular marker for human breast cancer. Oncol Rep 16: $1211-1214$

Luke C, Tracey E, Stapleton A, Roder D (2009) Exploring contrary trends in bladder cancer incidence, mortality and survival: implications for research and cancer control. Intern Med J 40: 357-362
Mahdy E, Pan Y, Wang N, Malmström PU, Ekman P, Bergerheim U (2001) Chromosome 8 numerical aberration and C-MYC copy number gain in bladder cancer are linked to stage and grade. Anticancer Res 21: $3167-3173$

Pollack JR, Sorlie T, Perou CM, Rees CA, Jeffrey SS, Lonning PE, Tibshirani R, Botstein D, Borresen-Dale AL, Brown PO (2002) Microarray analysis reveals a major direct role of DNA copy number alteration in the transcriptional program of human breast tumors. Proc Natl Acad Sci USA 99: $12963-12968$

Qiu D, Katanoda K, Marugame T, Sobue T (2009) A joinpoint regression analysis of long-term trends in cancer mortality in Japan (1958-2004). Int J Cancer 124: 443 - 448

Reichling T, Goss KH, Carson DJ, Holdcraft RW, Ley-Ebert C, Witte D, Aronow BJ, Groden J (2005) Transcriptional profiles of intestinal tumors in $\mathrm{Apc}$ (Min) mice are unique from those of embryonic intestine and identify novel gene targets dysregulated in human colorectal tumors. Cancer Res 65: 166-176

Saramäki OR, Porkka KP, Vessella RL, Visakorpi T (2006) Genetic aberrations in prostate cancer by microarray analysis. Int J Cancer 119: $1322-1329$

Scanlan MJ, Simpson AJ, Old LJ (2004) The cancer/testis genes: review, standardization, and commentary. Cancer Immun 4: 1

Shinoda Y, Kozaki K, Imoto I, Obara W, Tsuda H, Mizutani Y, Shuin T, Fujioka T, Miki T, Inazawa J (2007) Association of KLK5 overexpression with invasiveness of urinary bladder carcinoma cells. Cancer Sci 98: $1078-1086$

Simon R, Burger H, Semjonow A, Hertle L, Terpe HJ, Bocker W (2000) Patterns of chromosomal imbalances in muscle invasive bladder cancer. Int J Oncol 17: $1025-1029$

Sobin LH, Wittekind C (2002) TNM Classification of Malignant Tumours, 6th edn. International Union Against Cancer (UICC). Wiley-Liss: New York. pp 199-202

Stoehr R, Wissmann C, Suzuki H, Knuechel R, Krieg RC, Klopocki E, Dahl E, Wild P, Blaszyk H, Sauter G, Simon R, Schmitt R, Zaak D, Hofstaedter F, Rosenthal A, Baylin SB, Pilarsky C, Hartmann A (2004) Deletions of chromosome $8 \mathrm{p}$ and loss of sFRP1 expression are progression markers of papillary bladder cancer. Lab Invest 84: $465-478$

Sugimoto T, Seki N, Shimizu S, Kikkawa N, Tsukada J, Shimada H, Sasaki K, Hanazawa T, Okamoto Y, Hata A (2009) The galanin signaling cascade is a candidate pathway regulating oncogenesis in human squamous cell carcinoma. Genes Chromosomes Cancer 48: 132-142

Takemoto M, Shirahama T, Miyauchi T, Matsusako T, Kaneda N, Muramatsu H, Ozawa M, Ohi Y, Muramatsu T (1997) Metanestin, a glycoprotein with metastasis-associated expression in transitional cell carcinoma of the urinary bladder. Int J Cancer 74: 7-14

von Knobloch R, Bugert P, Jauch A, Kälble T, Kovacs G (2000) Allelic changes at multiple regions of chromosome 5 are associated with progression of urinary bladder cancer. J Pathol 190: 163-168

Yamamoto Y, Chochi Y, Matsuyama H, Eguchi S, Kawauchi S, Furuya T, Oga A, Kang JJ, Naito K, Sasaki K (2007) Gain of 5p15.33 is associated with progression of bladder cancer. Oncology 72: 132-138

Zaharieva BM, Simon R, Diener PA, Ackermann D, Maurer R, Alund G, Knönagel H, Rist M, Wilber K, Hering F, Schönenberger A, Flury R, Jäger P, Fehr JL, Mihatsch MJ, Gasser T, Sauter G, Toncheva DI (2003) Highthroughput tissue microarray analysis of $11 \mathrm{q} 13$ gene amplification (CCND1, FGF3, FGF4, EMS1) in urinary bladder cancer. J Pathol 201: $603-608$

Zhao J, Richter J, Wagner U, Roth B, Schraml P, Zellweger T, Ackermann D, Schmid U, Moch H, Mihatsch MJ, Gasser TC, Sauter G (1999) Chromosomal imbalances in noninvasive papillary bladder neoplasms (pTa). Cancer Res 59: 5687-5691 